\title{
Predictive Value of Transrectal Ultrasound in the Diagnosis of Prostate Cancer
}

\author{
Edoise M. Isiwele ${ }^{1}$, Anthonia A. Ikpeme ${ }^{2}$ \\ ${ }^{1}$ Urology Fellow, Department of Urology, University of Calabar Teaching Hospital, ${ }^{2}$ Associate Professor, Department of \\ Radiology, University of Calabar, Nigeria
}

Corresponding author: Dr Edoise M. Isiwele, Department of Urology, University of Calabar Teaching Hospital, Nigeria.

DOI: 10.21276/ijcmsr.2018.3.3.14

How to cite this article: Edoise M. Isiwele, Anthonia A. Ikpeme. Predictive value of transrectal ultrasound in the diagnosis of prostate cancer. International Journal of Contemporary Medicine Surgery and Radiology. 2018;3(3):C66-C69.

\section{A B S T R A C T}

Introduction: Prostate cancer incidence is on the rise worldwide with a significant number of patients being diagnosed with advanced disease. Transrectal ultrasound (TRUS) is increasingly becoming important in the routine evaluation of patients with suspected prostate cancer because of improvements in its technology. The role of TRUS in the detection of suspicious lesions aside from its use in guiding prostate biopsies, has been brought to question by some studies. Thus study was done to correlate TRUS with histopathology of biopsy specimens so as to determine how accurate it is in diagnosing prostate cancer.

Material and Methods: Adult male patients in whom digital rectal examination (DRE) findings indicated prostate biopsy underwent TRUS and subsequently had digitally-guided trucut sextant prostate biopsy. TRUS findings were then correlated with histopathology results. Data analysis was conducted using Statistical Package for Social Sciences (SPSS) version 16 and tests of correlation at $95 \%$ confidence limit, and $p$-value of $\leq 0.05$ were conducted.

Results: Forty five (45) adult male patients with mean age of 68.1 years and modal age group of 61 - 70 year were studied. The mean prostate volume was $88.5 \pm 70.0 \mathrm{~cm}^{3}$. Over $71 \%$ of patients had prostate glands with mixed echogenic features distantly followed by isoechoic features (15.6\%) ( $p>0.01$ ). Nearly $80 \%$ of the 32 patients who had mixed echogenic lesions had a histology of prostate cancer while all the patients with hyperechoic lesions had a benign histology.

Conclusion: The cancer detection rate of TRUS was found to be $73.3 \%$ in this study. TRUS, though not an accurate test is still relevant in the diagnosis of prostate cancer.

Key words: Correlation, Predictive Value, Prostate Cancer, Transrectal Ultrasound

\section{INTRODUCTION}

Prostate cancer incidence is estimated to be rising by $3 \%$ per annum worldwide and has been termed by expert epidemiologists as the 'oncological time bomb'. ${ }^{1}$ In Africa, the incidence was previously thought to be low but this has been disproved by results from several studies carried out in different parts of the continent. ${ }^{2,3}$ Most patients have disease that has extended beyond the confines of the gland at the time of diagnosis. ${ }^{4}$ In a study of prostate cancer patients over 10 years published earlier by Bassey and colleagues ${ }^{5}$ in Calabar, over $20 \%$ of patients were noted to have presented with metastatic prostate cancer. Early detection therefore is very important in the management of this disease. Modalities available for detection are digital rectal examination (DRE), prostate specific antigen (PSA) and transrectal ultrasound (TRUS) with the final diagnosis being made using histology of prostate biopsy specimens.

TRUS of the prostate was first reported by Wild and Reid in 1955 and popularized by Watanabe et al. in the early 1970s. ${ }^{6,7}$ Since then TRUS has increasingly becoming an important tool in the routine evaluation of patients suspected of having prostate cancer. This is because of the advances in ultrasound machine technology and intracavitary transducers with increasingly higher frequencies. ${ }^{8}$ However, the role of TRUS in the detection of suspicious lesions has been brought to question by some authors in their publications with some actually regarding TRUS as being only useful as a guide for prostate biopsy. ${ }^{9,10}$ TRUS is a procedure that uses sound waves to create a video image of the prostate gland. A small, lubricated probe placed in the rectum releases sound waves, which create echoes as they enter the prostate. The echoes that bounce back are sent to a computer that translates the pattern of echoes into a picture of the prostate. ${ }^{11}$ Isoechoic areas, which represent normal tissue, echo the same amount of sound waves as they received. Hypoechoic areas send back significantly fewer echoes than they received and often indicate the presence of cancer. Hyperechoic areas send back significantly more echoes than they receive and often indicate the presence of prostatic calcifications, or calculi in the prostate. ${ }^{11}$ The normal prostate gland has a homogenous, uniform echopattern. Most ultrasound-detected lesions found to be carcinoma are described as hypoechoic regions with irregular borders. However, not all hypoechoic regions 
in the peripheral zone are CaP. Potential hypoechoic lesions also include prostatitis, prostatic infarction, dilated glands, smooth muscle bundles, scarring, and prostatic intraepithelial neoplasia. ${ }^{12}$ Carcinoma may be undetectable by ultrasound or even hyperechoic. ${ }^{13,14}$ Only $60 \%$ of prostate cancers appear hypoechoic on ultrasound while most of the remaining cancers appear isoechoic with respect to the surrounding parenchyma. The etiology of hypoechogenicity is currently believed to be due to the replacement of the prostatic stroma with infiltrating glandular elements. ${ }^{15}$ The limitations of TRUS include frequent multifocality of cancer within the prostate, variable sonographic appearance of prostatic tumors, especially the substantial percentage of isoechoic prostate cancers and mostly the fact that it is operator dependent. ${ }^{16}$ Thus study was done to correlate

\begin{tabular}{|l|l|l|l|}
\hline Varaiable & Categories & Number & $\begin{array}{l}\text { Percentage } \\
(\%)\end{array}$ \\
\hline Echogenicity & Mixed & 32 & 71.1 \\
\hline & Isoechoic & 7 & 15.6 \\
\hline & Hypoechoic & 4 & 8.9 \\
\hline & Hyperechoic & 2 & 4.4 \\
\hline & Total & 45 & 100.0 \\
\hline Sonologic Diagnosis & CaP & 30 & 66.7 \\
\hline & BPH & 15 & 33.3 \\
\hline & Total & 45 & 100.0 \\
\hline
\end{tabular}

Table-1: Transrectal Ultrasound Features
TRUS with histopathology of biopsy specimens so as to determine how accurate it is in diagnosing prostate cancer.

\section{MATERIAL AND METHODS}

Consecutive adult male patients seen in the Urology unit of the University of Calabar Teaching Hospital Calabar over a period of one year, with lower urinary tract symptoms and other symptoms suggestive of prostate cancer and in whom DRE findings indicated prostate biopsy, were included in this study. Ethical approval was obtained from the ethical committee of the hospital. All patients already diagnosed with or on management for prostate cancer were excluded from the study. Transrectal ultrasound using Sonoscape $6000^{\circledR}$ digital colour doppler ultrasound system with a 5 MHz EC95 endocavitary transducer was performed. Insertion of the probe was preceded by a DRE to assess the anal sphincter and adequacy of the rectal space. With the patient in left lateral position, the probe was gently introduced with generous lubrication. The prostate was imaged in both transverse and sagittal planes. The echogenicity of the prostate was noted. Volume measurement of the prostate (using the formula: height $\mathrm{x}$ length $\mathrm{x}$ width $\mathrm{x} \pi / 6)^{64}$ and assessment of the shape and capsule of the prostate were carried out. Patients with abnormal DRE and TRUS findings with or without total PSA elevation had digitally-guided automated transrectal prostate biopsy after a prophylactic antibiotic therapy of oral Ciprofloxacin 500mg had been given thirty (30) minutes prior to the procedure. While in the left lateral position a

\begin{tabular}{|c|c|c|c|c|c|c|c|c|}
\hline \multirow[t]{2}{*}{$\begin{array}{l}\text { Echogenicity } \\
\text { Category }\end{array}$} & \multicolumn{2}{|c|}{ Histologic Diagnosis } & \multirow[t]{2}{*}{ Total } & \multirow[t]{2}{*}{$\begin{array}{c}\text { Regression } \\
\text { Coefficient (B) }\end{array}$} & \multicolumn{2}{|c|}{$\begin{array}{l}\text { 95\% Confidence Interval } \\
\text { For B }\end{array}$} & \multirow[t]{2}{*}{$\begin{array}{l}\text { Odds } \\
\text { Ratio }\end{array}$} & \multirow[t]{2}{*}{ P-Value } \\
\hline & $\mathrm{BPH}$ & $\mathrm{CaP}$ & & & & & & \\
\hline Constant & & & & .9 & & & 2.6 & .01 \\
\hline Hyperechoic & 2 & 0 & 2 & & & & & 0.24 \\
\hline Hypoechoic & 3 & 1 & 4 & -22.1 & -0.0 & +0.0 & 0.0 & 0.99 \\
\hline Isoechoic & 4 & 3 & 7 & -2.0 & 0.1 & 1.4 & 0.1 & 0.09 \\
\hline Mixed & 9 & 23 & 32 & -1.2 & .05 & 1.6 & 0.3 & 0.15 \\
\hline Total & 18 & 27 & 45 & & & & & \\
\hline
\end{tabular}

\begin{tabular}{|c|c|c|c|c|c|c|c|c|}
\hline \multirow{2}{*}{$\begin{array}{l}\text { Irregular } \\
\text { Prostate } \\
\text { Outline }\end{array}$} & \multicolumn{2}{|c|}{ Histologic Diagnosis } & \multirow[t]{2}{*}{ Total } & \multirow[t]{2}{*}{$\begin{array}{c}\text { Regression } \\
\text { Coefficient (B) }\end{array}$} & \multicolumn{2}{|c|}{$\begin{array}{l}\text { 95\% Confidence Interval } \\
\text { For B }\end{array}$} & \multirow[t]{2}{*}{$\begin{array}{l}\text { Odds } \\
\text { Ratio }\end{array}$} & \multirow[t]{2}{*}{ P-Value } \\
\hline & BPH & CaP & & & & & & \\
\hline Constant & & & & 1.1 & & & 3.0 & .01 \\
\hline No & 11 & 6 & 17 & -1.7 & .1 & .7 & .2 & .01 \\
\hline Yes & 7 & 21 & 28 & & & & & \\
\hline Total & 18 & 27 & 45 & & & & & \\
\hline
\end{tabular}

\begin{tabular}{|c|c|c|c|c|c|c|c|c|}
\hline \multirow[t]{2}{*}{$\begin{array}{l}\text { Sonologic } \\
\text { Diagnosis }\end{array}$} & \multicolumn{2}{|c|}{ Histologic Diagnosis } & \multirow[t]{2}{*}{ Total } & \multirow[t]{2}{*}{$\begin{array}{c}\text { Regression } \\
\text { Coefficient (B) }\end{array}$} & \multicolumn{2}{|c|}{$\begin{array}{l}\text { 95\% Confidence Interval } \\
\text { For B }\end{array}$} & \multirow[t]{2}{*}{$\begin{array}{l}\text { Odds } \\
\text { Ratio }\end{array}$} & \multirow[t]{2}{*}{ P-Value } \\
\hline & BPH & CaP & & & & & & \\
\hline Constant & & & & 1.0 & & & 2.8 & .01 \\
\hline $\mathrm{BPH}$ & 10 & 5 & 15 & -1.7 & .17 & .7 & .2 & .01 \\
\hline CAP & 8 & 22 & 30 & & & & & \\
\hline Total & 18 & 27 & 45 & & & & & \\
\hline
\end{tabular}




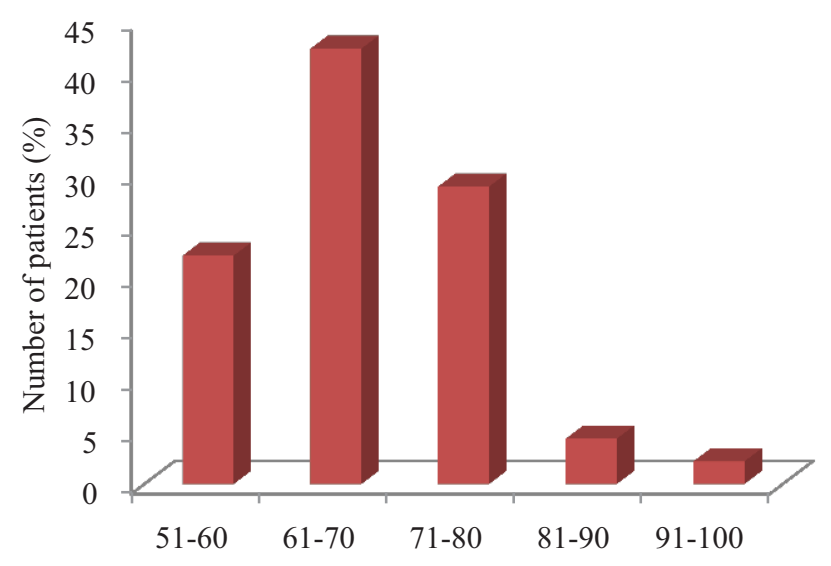

Age Group (Years)

Figure-1: Age Distribution of Patients

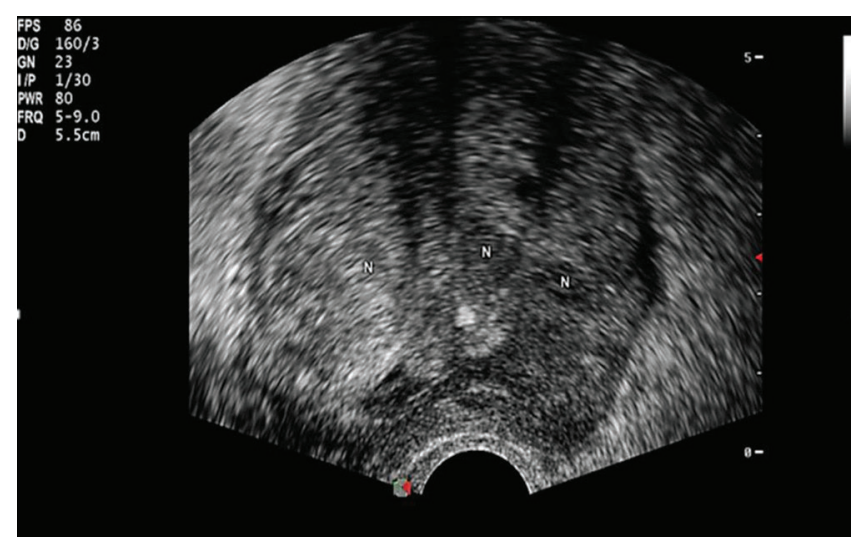

Figure-2: Image of a predominantly heterogenous prostate gland with focal areas of hypoechoic lesions (N) in an 80 year man.

well lubricated left index finger was used to guide a size 18G biopsy needle mounted on an automated spring loaded biopsy gun into the rectum to access the prostate. Six cores of prostatic tissue were obtained ( 2 each from the apex, midportion and base of the gland), fixed in Bouin solution and sent for histological analysis.

\section{STATISTICAL ANALYSIS}

Data was analysed using Statistical Package for Social Sciences (SPSS) version 16. Tests of correlation (Logistic regression and Pearson's chi square) at 95\% confidence limit and $p$-value of $\leq 0.05$ were conducted.

\section{RESULTS}

Forty five (45) adult male patients with mean age of 68.1 years and age range of $52-93$ years were studied. Most patients $(42.2 \%)$ were within the $61-70$ year age group. (Figure 1)

The mean prostate volume on TRUS was $88.5 \pm 70.0 \mathrm{~cm}^{3}$ with a range of $13.0-375.9 \mathrm{~cm}^{3}$. Most patients $(71.1 \%)$ had prostates with mixed echogenic features, followed by isoechoic features $(15.6 \%)(p>0.01)$. Twenty two out of the 30 patients with histologic diagnosis of prostate cancer had an irregular prostate outline on TRUS $(\mathrm{p}<0.01)$. (Tables 1 , 2 and 3)
Twenty two patients (73.3\%) out of 30 with sonologic diagnosis of prostate cancer had a positive histologic diagnosis. $(\mathrm{p}<0.01)$ (Table 4)

\section{DISCUSSION}

In this 12-month prospective study, the mean age was 68.1years with a standard deviation of 9.1 years. The age range was $52-93$ years with peak age range being $61-70$ years which accounted for $42.2 \%$ of patients with $77.8 \%$ of patients being above 61years of age. Osegbe ${ }^{3}$ had earlier reported a mean age of 68.3 years in a similar study in Lagos while Lopes et $\mathrm{al}^{8}$ recorded a mean age of 68.4 years in Portugal. Both studies recorded similar results as ours. Our study revealed a mean prostate volume of $88.5 \mathrm{~cm}^{3}$ with range of $13.0 \mathrm{~cm}^{3}-376.0 \mathrm{~cm}^{3}$ with majority of patients having mixed echogenicity (71.1\%). Ahmed and colleagues ${ }^{17}$ in Zaria found a mean prostate size of $66.8 \mathrm{~g}$ with a range of $15-219 \mathrm{~g}$. Eri and colleagues ${ }^{18}$ in Norway recorded a mean prostate volume of $58.0 \mathrm{ml}$ with range of $26.6-164.8 \mathrm{ml}$. The mean prostate volumes recoded in both Nigerian studies were larger and the ranges wider than those of the Norwegian study. Most patients $(71.1 \%)$ had prostate glands with mixed echogenic features, followed distantly by isoechoic features (15.6\%). Mixed echogenicity on TRUS correlated more with a histologic diagnosis of $\mathrm{CaP}$ as $71.9 \%$ of the 32 patients who had mixed echogenic features had a histology of prostate cancer. Over forty-two (42.9) percent of patients with isoechoic lesions were found to have $\mathrm{CaP}$, while $25 \%$ of those with hypoechoic lesions had a final diagnosis of CaP. None of those with hyperechoic lesions were found to have prostate cancer on histology. Hypoechoic nodules located in the peripheral region have been shown to have the highest predictive value in the detection of prostate cancer ${ }^{19}$ and more studies in the past had noted hypoechoic lesions to correlate more with a histologic diagnosis of $\mathrm{CaP} .{ }^{15,20}$ This was the pattern also recorded in the Zaria study where hypoechoic lesions were found to correlate more with a histologic diagnosis of $\mathrm{CaP}$. Our findings however were different as recorded above. In a study by Ellis and colleagues ${ }^{21}$ on 1001 patients in Seattle USA, hypoechoic lesions were more than twice as likely as isoechoic lesions to contain malignancy on biopsy but even then, as high as $37.6 \%$ of the cancers were found in isoechoic sectors. They found that performing biopsy of only hypoechoic sectors would have misdiagnosed $24.6 \%$ of the patients with prostate cancer. Our findings have gone on to further prove the fact that a significant proportion of prostate cancer cases can be missed when the focus is on hypoechoic nodules. Rather, loss of homogeneity should be considered as being more suggestive even though a significant proportion of cancers were also found in isoechoic lesions in our study. All the hyperechoic lesions in our study were found to be benign. Ahmed et al as well as Lee et al ${ }^{17,22}$ had previously recorded similar findings in earlier studies. Irregular prostate outline on TRUS was found to have a statistically significant positive correlation with histologic diagnosis of prostate cancer as $75 \%$ of patients with irregular capsular outline had a histology of $\mathrm{CaP}(\mathrm{p}<0.05)$. Therefore the presence of an irregular prostate outline on TRUS should strongly suggest the presence of CaP. Twenty two patients 
out of 30 with sonologic diagnosis of prostate cancer had a histologic diagnosis of prostate cancer $(p<0.01)$, giving a cancer detection rate of $73.3 \%$. In a similar study carried out by Lopes et $\mathrm{al}^{8}$ in Brazil, suspicious nodules were detected in 34 patients out of which 25 were malignant giving a positive predictive value of $74 \%{ }^{8}$. Sibley et $\mathrm{al}^{23}$ had reported that when pathology reports were correlated with the findings on DRE and TRUS, both DRE and TRUS were positive in $46 \%$ of subjects, DRE was negative and TRUS, positive in $30 \%$ and DRE was positive when TRUS was negative or equivocal in $14 \%$ of subjects. The diagnostic accuracy rate for prostate cancer in another study by Ahmad and Dadgar was $67.27 \%$. The cancer detection rate recorded in our study was comparable with that in the study by Lopes et al and higher than that recorded by Sibley and Ahmad and Dadgar.

\section{CONCLUSION}

Transrectal ultrasound findings in this study have been found to correlate well with a histopathologic diagnosis of prostate cancer with the cancer detection rate of TRUS found to be $73.3 \%$. Specific features like irregularity of the prostate correlated independently with a histology of prostate cancer. TRUS of the prostate, though with limited potential, is still quite relevant in the diagnosis of prostate cancer in addition to being used as a guide for prostate biopsies.

\section{REFERENCES}

1. Cussenot O. Genetic susceptibility to prostate cancer. In: Fouad K Habib, editor. The prostate: New concepts and developments. Second. London and New York: Taylor and Francis group; 2004. p. 54-62.

2. Ogunbiyi JO, Shittu OB. Increased incidence of prostate cancer in Nigerians. J Natl Med Assoc. 1999;91(3):15964.

3. Osegbe DN. Prostate cancer in Nigerians: Facts and nonfacts. J Urol. 1997;157(4):1340-3.

4. Cooner WH. Rectal examination and ultrasonography in the diagnosis of prostate cancer. Prostate Suppl. 1992;4:3-10.

5. Bassey I-AE, Isiwele EM, Debua A. Prognostication studies of prostate cancer in Black Africa: Findings from Calabar, South-South Nigeria. Int J Cont Med Res. 2018;5(5):E1-E5.

6. Wild J, Reid J. Fourth Annual Conference in Ultrasound Therapy. In 1955.

7. Watanabe H, Kato H, Kato T. Diagnostic application of ultrasonotomography to the prostate. Nippon Hinyokika Gakkai Zasshi. 1968;59:273-9.

8. Lopes PM, Ramos R, Sousa P. The role of transrectal ultrasound in the diagnosis of prostate cancer: new contributions. Radiol Bras. 2015;48(1):7-11.

9. Kuligowska E, Ma B, Hm F, Blake M. Predictors of prostate carcinoma: accuracy of gray-scale and color Doppler US and serum markers. Radiology. 2001;220(3):757-64.

10. Yacoub J, Verma S, Moulton J, Eggener S, Aytekin O. Imaging-guided prostate biopsy : conventional and emerging techniques. Radiographics. 2012;32(3):81937.

11. Prostate Cancer [Internet]. UPMC CancerCenter
Prostate Cancer Information. 2014. p. 1-2. Available from: http://www.upmccancercenter.com/cancer/ prostate/biopsyultrasound.cfm

12. Langer JE. The Current Role of Transrectal Ultrasonography in the Evaluation of Prostate Carcinoma. Semin Roentgenol. 1999;XXXIV(4):284-94.

13. Kramer A, Siroky MB. Neoplasms of the genitourinary tract. In: Siroky MB, Oates RD, Babayan RK, editors. Handbook of Urology:Diagnosis and therapy. Third. Philadelphia: Lipincott Williams and Wilkins; 2004. p. 250-300.

14. Walz J, Loch T, Salomon G, Wijkstra H. Lokale Bildgebung der Prostata. In: Lepor H, Lawson R, editors. Urologe - Ausgabe A. First. Philadelphia: WB Saunders Co; 2013. p. 490-6.

15. Hernandez AD, Smith JAJ. Transrectal ultrasonography for the early detection and staging of prostate cancer. Urol Clin North Am. 1990;17(4):745-57.

16. Clements R. The role of transrectal ultrasound in diagnosing prostate cancer. Curr Urol Rep. 2002;3(3):194-200.

17. Ahmed M, Maitama H, Bello A, Kalayi G, Mbibu H. Transrectal ultrasound findings in patients with advanced prostate cancer. Ann Niger Med. 2010;4(2):59.

18. Eri L, Thomassen H, Brennhovd B, Haheim L. Accuracy and repeatability of prostate volume measurements by transrectal ultrasound. Prostate Cancer Prostatic Dis. 2002;5(1):273-8.

19. Pinto F, Totaro A, Palermo G, Calarco A, Sacco E, D'Addessi A, et al. Imaging in prostate cancer staging: Present role and future perspectives. Urol Int. 2012;88(2):125-36.

20. Abdulkareem F. Epidemiology and incidence of common cancers in Nigeria. In: Cancer registry and epidemiology worshop April 2009. 2009. p. 1-58.

21. Ellis WJ, Chetner MP, Preston SD, Brawer MK. Diagnosis of prostatic carcinoma: The yield of serum prostate specific antigen, digital rectal examination and transrectal ultrasonography. J Urol. 1994;152(5 Pt 1):1520-5.

22. Lee F, Gray J, McLeary R, McHugh T, Solomon M, Kumasaka G, et al. Prostatic evaluation by transrectal sonography: criteria for diagnosis of early carcinoma. Radiology. 1986;158(1):91-5.

23. Sibley RM, Sibley AF. Correlation of digital rectal examination, prostate specific antigen, and transrectal ultrasound in prostate carcinoma in African Americans. J Natl Med Assoc. 1996;89(5):318-23.

Source of Support: Nil; Conflict of Interest: None

Submitted: 01-07-2018; Accepted: 02-08-2018; Published online: 13-08-2018 